\title{
Evaluation of the morphological parameters of aroeira seedlings (Schinus terebinthifolius Raddi.) in biodegradable tubes
}

\section{Avaliação dos parâmetros morfológicos de mudas de aroeira (Schinus terebinthifolius Raddi.) em tubetes biodegradáveis}

\author{
Cristiano Cunha Costa ${ }^{1}$ \\ ${ }^{1}$ Universidade Federal de Sergipe. \\ cristianocunha1982@hotmail.com
}

Recebido em agosto 2020 e aceito em outubro de 2020.

\begin{abstract}
Resumo - O objetivo deste estudo foi avaliar os parâmetros morfológicos de mudas de aroeira em tubetes biodegradáveis. Foram comparados tubete de polipropileno (PP) e o tubete comercial SIS BCG® (Biodegradável). Após 90 dias, foram analisados: altura $(\mathrm{H})$, diâmetro do colo (DC), massa seca da parte aérea (MSPA), massa seca da raiz (MSR), índice de qualidade de Dickson (IQD) e índice de Robustez (IR) das mudas de aroeira. Observou-se que as mudas de aroeira não apresentaram diferença estatística entre os tipos de tubetes para todos os parâmetros de altura, diâmetro do colo, massa seca da parte aérea, massa seca da raiz e índice de qualidade de Dickson. Por outro lado, houve diferença estatística entre os tubetes apenas para o índice de rusticidade, sendo que as mudas tiveram melhor índice para o tubete biodegradável. Portanto, os tubetes biodegradáveis podem ser utilizados para a produção de mudas em viveiro florestal, pois não influenciaram negativamente nos parâmetros de crescimento e desenvolvimento de mudas de espécies florestais nativas, ou seja, não de degrada durante a permanência em viveiro, permitindo o crescimento até que as mudas atingissem os parâmetros necessários para ir a campo.
\end{abstract}

Palavras-chave: Espécie nativa. Sustentabilidade. Setor florestal. Viveiro florestal

\begin{abstract}
The aim of this study was to evaluate the morphological parameters of aroeira seedlings in biodegradable tubes. Polypropylene (PP) tubes and commercial SIS BCG® tubes (Biodegradable) were compared. After 90 days, height $(\mathrm{H})$, neck diameter (DC), dry shoot weight (MSPA), dry root weight (MSR), Dickson's quality index (IQD) and Robustness index (IR) were analyzed ) of mastic seedlings. It was observed that the aroeira seedlings showed no statistical difference between the types of tubes for all parameters of height, neck diameter, dry mass of the aerial part, dry mass of the root and Dickson's quality index. On the other hand, there was a statistical difference between the tubes only for the rusticity index, and the seedlings had a better index for the biodegradable tube. Therefore, biodegradable tubes can be used for the production of seedlings in a forest nursery, as they did not negatively influence the growth and development parameters of seedlings of native forest species, that is, they do not degrade during their stay in the nursery, allowing the growth until that the seedlings reach the necessary parameters to go to the field.
\end{abstract}


Keywords: Native species. Sustainability. Forestry sector. Forest nursery

\section{Introdução}

A espécie Schinus terebinthifolius Raddi, da família da Anacardeaceae, é conhecida, popularmente, como aroeira vermelha ou pimenta-rosa (LORENZI, 2008). Sua ocorrência, no Brasil, dá-se nas regiões Norte, Sul, Sudeste, Centro-Oeste e Nordeste, estando presente nas vegetações de caatinga, cerrado e mata atlântica (PAREYN et al., 2018). Seus frutos são utilizados na culinária e as cascas do caule são utilizadas para combater inflamações de várias origens, pois apresentam propriedades anti-inflamatórios e cicatrizantes. É uma espécie muito usada na arborização urbana, como cercas vivas e na recuperação de áreas degradadas (CARMELLO-GUERREIRO; PAOLI, 2002; AMORIM; SANTOS, 2003; LORENZI; MATOS, 2008).

Devido a seu valor econômico, sua adaptação a diferentes condições climáticas e tolerância a seca, a aroeira é considerada umas das mais promissoras espécies arbóreas nativas para serem empregadas no enriquecimento ou recomposição de reservas legais e na recuperação de áreas degradadas. O seu plantio, também, contribui para propagação e conservação da própria espécie (CORADIN et al., 2018).

Diante desse contexto, a produção de mudas nativas é importante quanto estratégia de recuperação, regeneração ou reflorestamentos florestais, devendo as mesmas serem de boa qualidade, implicando em maiores taxas de crescimento e sobrevivência em campo após plantio e diminuindo gastos com tratos culturais e replantio (MARINHO et al., 2017; RODRIGUES et al., 2020). Assim, alguns parâmetros morfológicos como, por exemplo, altura, diâmetro do colo, índice de rusticidade, massa seca da parte aérea, massa seca da raiz e índice de Dickson são utilizados para avaliar a qualidade das mudas em viveiro florestal (CARGNELUTTI FILHO et al., 2018; ABREU et al., 2019; PAIVA et al., 2019; SANTANA et al., 2019).

No que se refere ao setor florestal, os tubetes utilizados na produção de mudas florestais são de polietileno ou polipropileno, produzidos com derivados do petróleo, tornando-se um grave problema ambiental, pois são oriundos de uma fonte não renovável e geram resíduos de descarte que demoram séculos para se degradar (MOREIRA et al., 2010). Dessa maneira, a preocupação ambiental está no descarte e no longo tempo de degradação dos polímeros convencionais.

Apesar de existir alguns trabalhos relatando a relação das características morfológicas com o crescimento das mudas em viveiro florestal (OLIVEIRA; FIORINE, 2006; BRANT et al., 2013; FERRAZ et al., 2015; GUERRA et al., 2017), não se teve nenhuma pesquisa conclusiva, pois os tubetes biodegradáveis não suportavam as condições ambientais nos viveiros ou não favoreciam condições necessárias ao crescimento das mudas, uma vez que não conseguiam manter sua estrutura física, implicando nos parâmetros morfológicos necessários a atingir a qualidade padrão de ir à campo (NOVAES et al., 2014). Nesse sentido, experiências concluem que essas características adquiridas em viveiro são importantes para o sucesso do desempenho das mudas em situações de campo. 


\section{Revista Ambientale}

Revista da Universidade Estadual de Alagoas/UNEAL e-ISSN 2318-454X, Ano 12, Vol. 12 (3), julho/outubro (2020).

Assim, o presente estudo teve como objetivo avaliar os parâmetros morfológicos de mudas de aroeira (Schinus terebinthifolius Raddi.) em tubetes biodegradáveis em viveiro florestal como estratégia de uma produção mais sustentável e ecologicamente mais adequada.

\section{Materiais e métodos}

\section{Escolha dos tubetes}

Foram utilizados tubetes de polipropileno (PP) e o tubete comercial SIS BCG® (Biodegradável) o qual é um tubete biodegradável fornecido, gentilmente, pela Empresa Correia Neto.

Os tubetes utilizados no estudo possuem as seguintes dimensões: diâmetro superior de $3,5 \mathrm{~cm}$; diâmentro inferior de $2,8 \mathrm{~cm}$ e altura de $12 \mathrm{~cm}$ (Figura 1).

Figura 1. Tubetes biodegradável (SIS BCG®) (A) e tubete de polipropileno (B) utilizados no experimento.

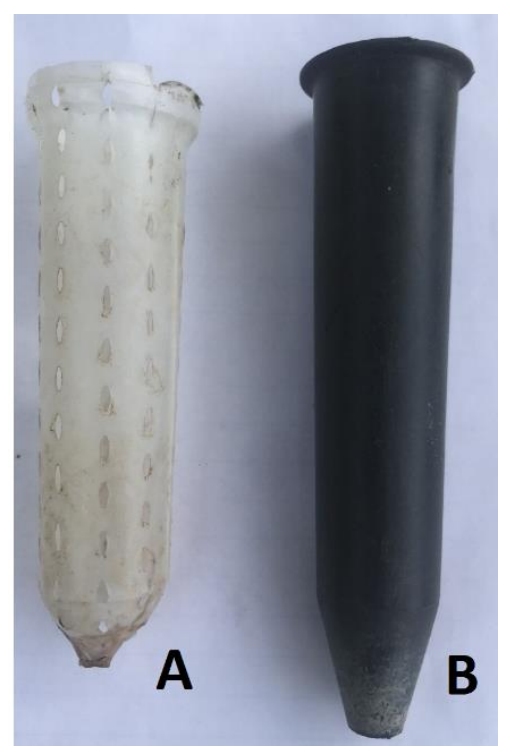

\section{Escolha da espécie}

A escolha das espécies (Tabela 1) se deu por meio das potencialidades para a recuperação de áreas degradadas e levando-se em consideração as características ecológicas, econômicas, sociais e silviculturais da espécie florestal. 


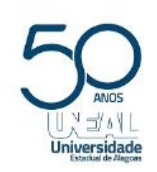

\section{Revista Ambientale}

Revista da Universidade Estadual de Alagoas/UNEAL

e-ISSN 2318-454X, Ano 12, Vol. 12 (3), julho/outubro (2020).

Tabela 1. Espécie selecionada para o estudo da viabilidade dos tubetes biodegradáveis em viveiro florestal.

\begin{tabular}{cccc}
\hline Nome vulgar & Nome científico & Família & CS \\
\hline Aroeira vermelha & Schinus terebinthifolius Raddi & Anacardiaceae & $\mathrm{P}$ \\
\hline
\end{tabular}

Classificação sucessional: P - Pioneira.

A classificação sucessional está relacionada ao tempo de permanência em viveiro das mudas das espécies selecionadas. Para Scheer et al. (2017), o tempo médio para a produção de mudas florestais nativas classificadas como pioneira é de 90 dias, aproximadamente.

\section{Produção de mudas}

O experimento foi montado no viveiro florestal do Departamento de Ciências Florestais do Campus São Cristóvão da Universidade Federal de Sergipe, município de São Cristóvão - SE (1055'32"S e 3706’08" W).

O clima local, segundo a classificação de Köppen, é do tipo AS', ou seja, período chuvoso ocorre entre os meses de abril e agosto, sendo a temperatura média oscila entre 26 e $30{ }^{\circ} \mathrm{C}$, a umidade relativa do ar média é elevada (75\% a $\left.87 \%\right)$ e a precipitação média anual de $1.450 \mathrm{~mm}$ (BRASIL, 1972b).

O experimento foi realizado em Delineamento em Blocos Inteiramente Casualizados (DBC), composto por 2 tratamentos, com 3 repetições de 10 mudas, totalizando 30 indivíduos florestais por tratamento.

Foi realizada a semeadura direta nos tubetes (biodegradável e PP), em estufa sombreada (sombrite $50 \%$ ) e irrigado 2 vezes ao dia. Quando as mudas atingiram de $5 \mathrm{~cm}$, aproximadamente, foi realizado o desbaste, permanecendo no telado de 15 a 20 dias e, em seguida, foram levadas em pleno sol para aclimatação.

Como substrato, utilizou-se o Plantemax, terra preta e areia, na proporção 3:1:1. Uma adubação inicial foi realizada com $750 \mathrm{~g}$ de superfosfato simples $+125 \mathrm{~g}$ de cloreto de potássio $+75 \mathrm{~g}$ de FTE-BR 12 para cada $\mathrm{m}^{3}$ de substrato, e a de cobertura foi iniciada a partir de 30 dias após a emergência, utilizando-se $60 \mathrm{~g}$ de cloreto de potássio $+25 \mathrm{~g}$ de sulfato de amônio diluído em 10 L de água.

A permanência em viveiro correspondeu ao período de 3 meses de uso dos tubetes, pois é o tempo médio de crescimento em que as mudas pudessem obter parâmetros de qualidade de desenvolvimento (altura, formação do sistema radicular, diâmetro do colo e condições nutricionais) considerados ideais para, então, ser levada à campo para plantio.

\section{Avaliação da qualidade das mudas}

As avaliações ocorreram quando as mudas apresentaram ao menos um dos atributos de qualidade adequados para plantio em campo, sendo a altura mínima de $22 \mathrm{~cm}$ e diâmetro de colo mínimo de $3 \mathrm{~mm}$, conforme sugerido por Fonseca et al. (2002). Os parâmetros analisados foram: altura $(\mathrm{H})$, diâmetro do colo (DC), massa seca da parte aérea 
(MSPA), massa seca da raiz (MSR), índice de qualidade de Dickson (IQD) e índice de Robustez (IR).

A altura de parte aérea $(\mathrm{cm})$ foi medida com régua graduada do colo da planta até o meristema apical. O diâmetro do colo da muda foi tomado com paquímetro digital, com precisão de 0,01 mm. Para quantificação da matéria seca, o sistema radicular foi separado da parte aérea e ambos foram secos em estufa de circulação forçada a $60^{\circ} \mathrm{C}$, até atingir peso constante, logo depois, pesadas em balança analítica com precisão de 0,01 g. Com base nos parâmetros morfológicos avaliados, foram calculados o Índice de Qualidade de Dickson (IQD) (DICKSON et al., 1960) e o Índice de Robustez (IR) (MELO et al., 2018), a partir das equações abaixo:

$$
\mathrm{IQD}=\frac{\mathrm{MST}}{\mathrm{H} / \mathrm{DC}+\mathrm{MSPA} / \mathrm{MSR}}
$$

$$
\mathrm{IR}=\frac{\mathrm{H}}{\mathrm{DC}}
$$

$$
\begin{aligned}
& \text { Onde: } \text { MST = Massa Seca Total (MSPA+MSR) (g); } \\
& \text { MSPA = Massa Seca da Parte Área (g); } \\
& \text { MSR = Massa Seca da Raiz (g); } \\
& \mathrm{H}=\text { Altura }(\mathrm{cm}) \text {; } \\
& \mathrm{DC}=\text { Diâmetro do Colo }(\mathrm{mm}) \text {. }
\end{aligned}
$$

Os resultados obtidos foram submetidos à análise estatística pelo teste $\mathrm{T}$ de Student, com intervalo de confiança de $95 \%$, para verificar se há diferença significativa entre as médias. Para isso, usou-se o software SPSS statistics, versão 20.

\section{Resultados e discussão}

Os resultados obtidos permitiram, segundo a análise estatística, fazer uma análise sobre as características morfológicas (altura, diâmentro do colo, massa seca da parte aérea, massa seca da raiz, índice de rusticidade e índice de qualidade de Dickson) e os diferentes tipos de tubetes testados.

Observa-se que as mudas das espécies florestais de aroeira não apresentaram diferença estatística para o crescimento em altura em relação aos tipos de tubetes estudados (Figura 1).

A altura da parte aérea $(\mathrm{H})$ é uma das características mais importantes para avaliar o padrão de qualidade de mudas de espécies florestais, correlacionando-se positivamente com o crescimento no campo (PAIVA et al., 2019). Essa característica morfológica é uma das mais utilizadas, por ser de fácil observação nos viveiros e não precisar destruir as mudas (SANTANA et al., 2019).

Entretanto, a utilização dessa característica para comparar a qualidade das mudas é recomendada por Rodrigues et al. (2020) somente quando as mudas forem da mesma espécie e quando as técnicas de produção e as condições ambientais forem semelhantes. 
Figura 1. Crescimento em altura das mudas de aroeira em relação aos tubetes estudados.

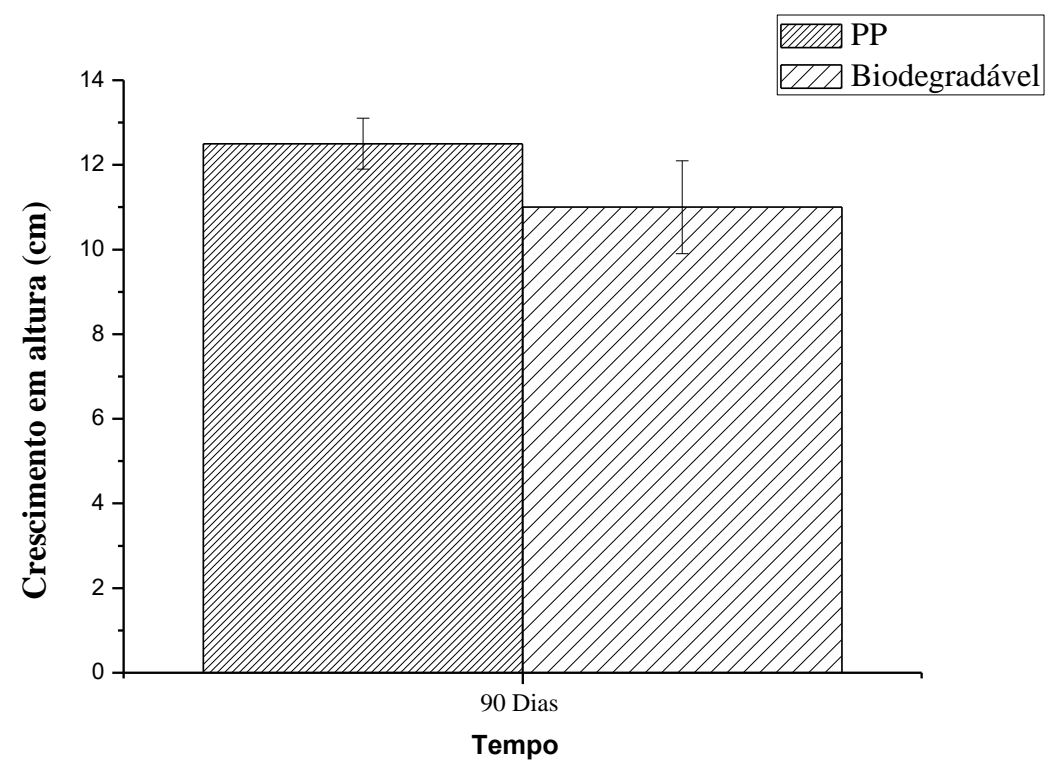

Para o crescimento em diâmetro, observa-se que as mudas produzidas nos tubetes biodegradáveis atingiram $1,1 \mathrm{~mm}$ e as mudas dos tubetes de polipropileno 1,3mm, não havendo diferença estatística para essa variável em relação aos recipientes estudados (figura 2)

Figura 2. Crescimento em diâmetro do colo para as mudas de aroeira.

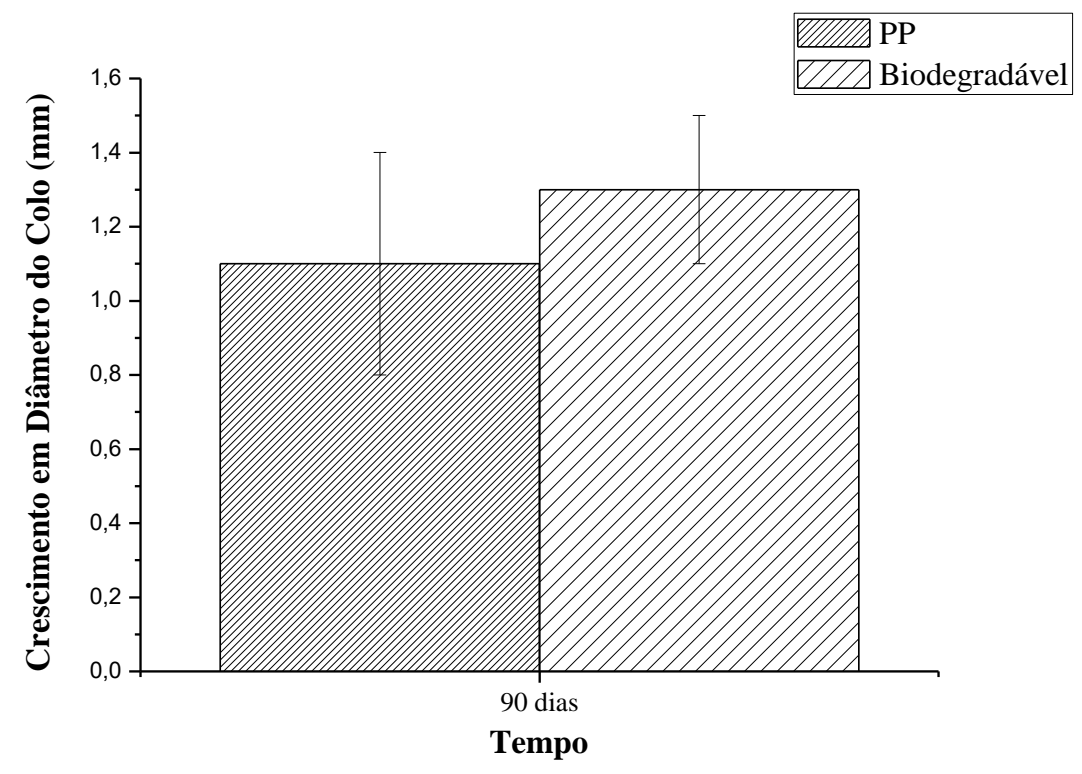

O diâmetro do coleto (DC), também, possui fácil mensuração e não é um método destrutivo. Apenas o diâmetro do coleto ou sua combinação com a altura representa uma das 
melhores características para avaliar o padrão de qualidade de mudas (CARGNELUTTI FILHO et al., 2018).

Segundo esses autores, o diâmetro do colo chega a explicar 70 a $80 \%$ das diferenças que existem no peso de matéria seca das mudas (CARGNELUTTI FILHO et al., 2018). O valor do diâmetro do coleto é uma variável dependente da ecologia de cada espécie florestal como reportados em alguns trabalhos como os de Marinho et al. (2017) e Paiva et al. (2019). Assim, segundo Paiva et al. (2019), não existe um valor que define o padrão de qualidade de mudas, pois isto depende da espécie, do local, dos métodos e das técnicas de produção.

Para os parâmetros de altura e diâmetro, José et al. (2009) concluíram que mudas de aroeira, para ser considerada de qualidade para campo, devem ter no mínimo 3,0 $\mathrm{mm}$ de diâmetro e para Oliveira et al. (2016), a altura deve estar entre 20 e $30 \mathrm{~cm}$.

No entanto, as mudas de aroeira não atingiram os padrões morfológicos considerados de qualidade para serem levados à campo de reflorestamento/recuperação florestal dentro do período do experimento. Tal fato pode ser explicado pelo tamanho do tubete utilizado para a produção das mudas, uma vez que é reportado na literatura que o tamanho do recipiente é um limitador de crescimento das espécies florestais (JOSÉ et al., 2009; OLIVEIRA et al., 2016; COSTA et al., 2020).

Além disso, as variáveis altura da planta e diâmetro de caule são comumente utilizadas para avaliar a qualidade da muda, sendo que quanto maior o diâmetro do coleto, mais resistente a mesma será e maiores serão a possibilidade de resistência ao tombamento e a sobrevivência no campo (PAIVA; SOBRINHO et al., 2010).

É interessante destacar que há um índice que co-relaciona a altura e o diâmetro do colo da muda florestal, é o Índice de Rusticidade. Na figura 3, estão os resultados sobre o IR para as mudas da espécie aroeira. Nota-se que as mudas apresentaram valores do índice de rusticidade de 11,2 e 8,4 para os tubetes de polietileno e tubetes biodegradáveis, respectivamente, não apresentando diferença estatística entre si pelo teste T de Student.

Figura 3. Índice de rusticidade para as mudas de aroeira após os 90 dias de experimento.

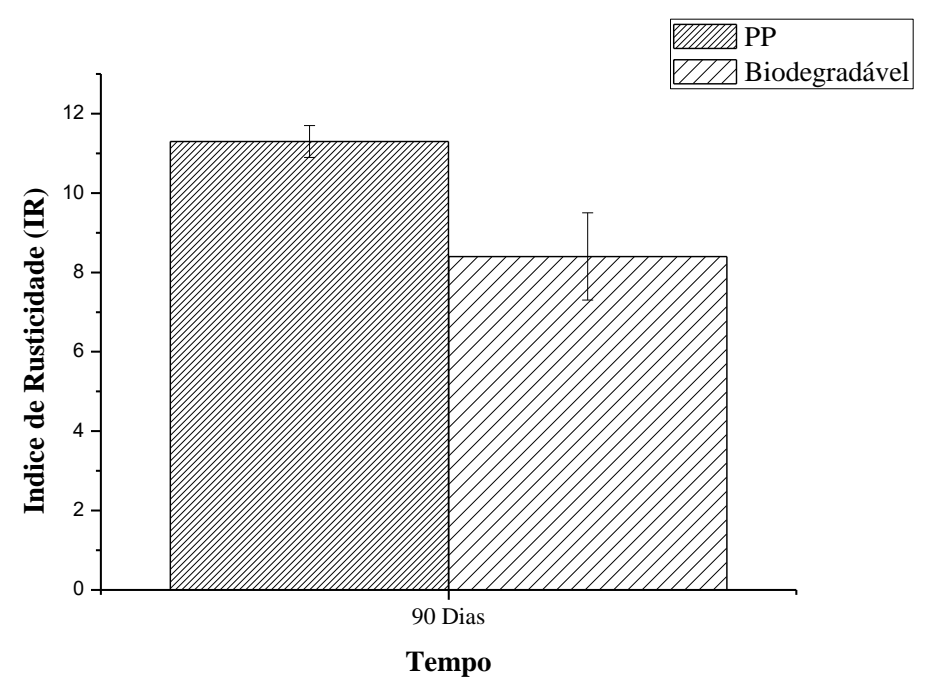

Birchler et al. (1998) recomendam que mudas de qualidade devam apresentar valores de relação H/D inferiores a 10. Neste contexto, acredita-se que as mudas produzidas nos 
tubetes biodegradáveis obtiveram valores satisfatórios de relação H/D, visto que apresentaram valores abaixo de 10 .

A relação H/DC representa o equilíbrio de desenvolvimento das mudas, pois é através da relação destas variáveis que se obtém o Índice de Robustez (IR), e quanto menor o seu valor, melhor é a qualidade da muda e maior a capacidade de sobrevivência e estabelecimento após o plantio (CARGNELUTTI FILHO et al., 2018).

Plantas que apresentam uma razão alta, tendem a possuir uma altura elevada em relação a um diâmetro do coleto pequeno, as tornando mais suscetíveis a tombamentos, enquanto que plantas com uma razão pequena tendem a ter uma altura e diâmetro do coleto mais equilibrada, o que lhes assegura maior resistência e melhor fixação ao solo (OLIVEIRA et al., 2020).

No entendimento de Carneiro (1995), os valores ideais para essa relação devem estar entre 5,4 e 8,1 demonstrando o equilíbrio de crescimento das mudas. Os valores relacionados a esse parâmetro, encontrados no presente trabalho, são inferiores e iguais a faixa considerado ideal.

A produção de biomassa seca tem sido considerada um dos melhores parâmetros morfológicos para se avaliar a qualidade de mudas. Muitos viveiros, não acreditam ser viável a sua determinação, principalmente por envolver o método da destruição completa da muda e a utilização de estufas (ALVES; FREIRE, 2017). Deste modo, torna-se interessante destacar a importância das análises da massa seca da parte aérea e a massa seca da raiz das mudas de aroeira durante os 90 dias do experimento.

Os resultados da análise da massa seca da parte aérea estão apresentados na figura 5. Verifica-se que não há diferença estatística entre os diferentes tipos de tubetes utilizados para a produção de mudas de aroeira em viveiro florestal (figura 4).

Figura 4. Massa seca da parte aérea das mudas de aroeira.

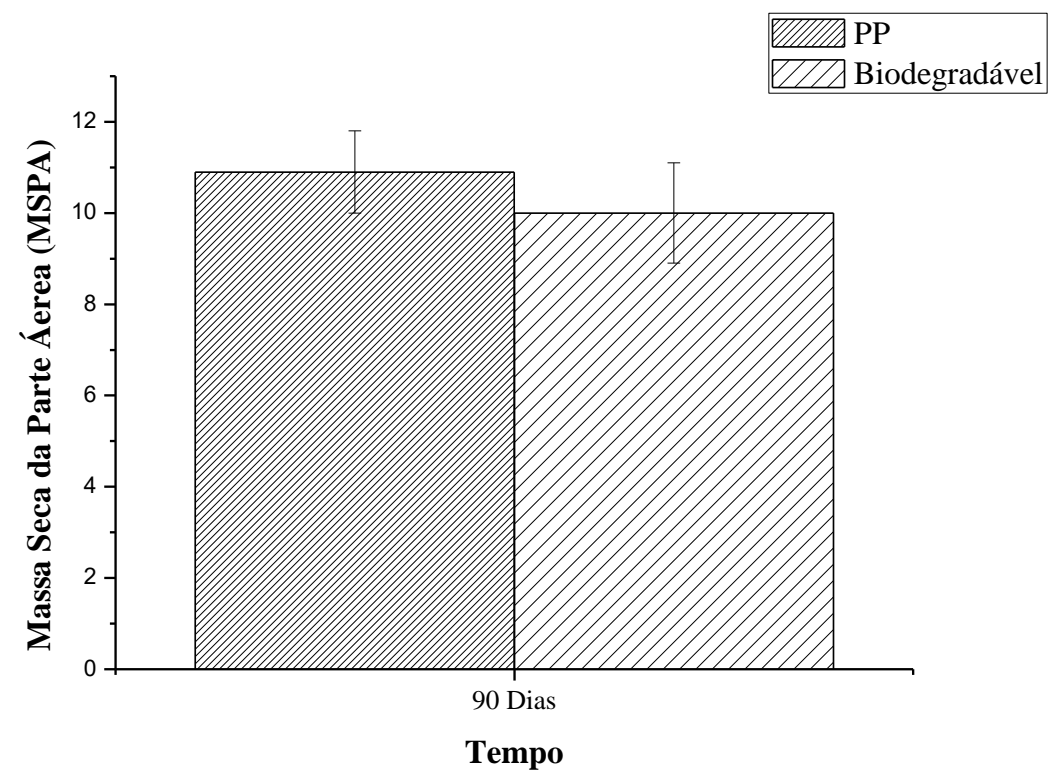

A produção de biomassa é uma das melhores características para avaliar a qualidade das mudas, apesar de destrutiva, pois reflete a fotossíntese líquida da planta, ou seja, é 


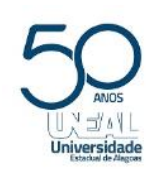

\section{Revista Ambientale}

Revista da Universidade Estadual de Alagoas/UNEAL

e-ISSN 2318-454X, Ano 12, Vol. 12 (3), julho/outubro (2020).

possível analisar o crescimento em altura e diâmetro que a espécie florestal obteve durante a sua permanência em viveiro e se está em condições para ir à campo (ALVES; FREIRE, 2017).

Com relação a massa seca da raiz (MSR), os resultados mostram que não houve diferença estatística para as mudas de aroeira nos tubetes estudados (figura 5).

Figura 5. Massa seca da raiz (MSR) para as mudas de aroeira

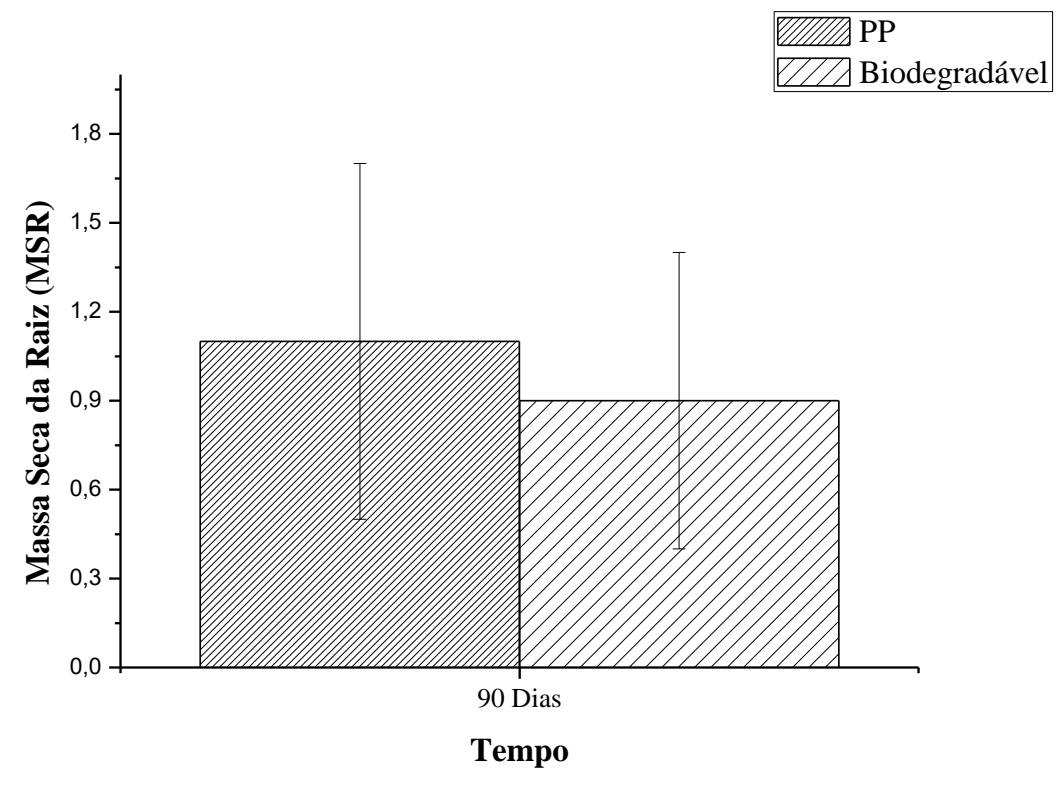

O sistema radicular, para Gomes e Freire (2019), deve ter um tamanho suficiente para permitir o suprimento adequado de água para a parte aérea. Plantas que desenvolvem maior sistema radicular durante sua permanência em viveiro, em determinada condição, apresentam maior probabilidade de sobrevivência após plantio em campo, uma vez que o maior investimento em biomassa radicular garante uma melhor aclimatação das plantas em campo do que aqueles com sistemas radiculares reduzidos (MEIRELES et al., 2020).

Para a Massa Seca da Parte Aérea (MSPA) e a Massa Seca Radicular (MSR), os resultados encontrados corroboram com os obtidos por José et al. (2009) e Abreu et al. (2017) para mudas de aroeira.

Essa boa relação entre MSPA e a MSR ser explicado pelo fato de que os tubetes propiciaram uma condição adequada do substrato, permitindo maior aeração do solo e manutenção da umidade, permitindo condições favoráveis para que as mudas de aroeira absorvessem os nutrientes do solo e a umidade, fazendo-se da particularidade ecológica da espécie em crescer de forma rápida. Assim, no entendimento de Abreu et al. (2017), o bom desenvolvimento das mudas de aroeira ocorreu devido a interação entre as condições propícias criadas pelos tubetes e a ecologia da espécie.

Tal resultado diverge com alguns estudos na literatura. Ferraz et al. (2015), Antoniazzi et al. (2013) e Santana et al. (2019) observaram que mudas de espécies nativas não tiveram 


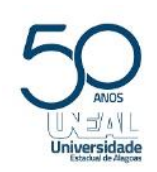

\section{Revista Ambientale}

Revista da Universidade Estadual de Alagoas/UNEAL e-ISSN 2318-454X, Ano 12, Vol. 12 (3), julho/outubro (2020).

resultados satisfatórios em tubetes biodegráveis, pois as mudas apresentaram valores inferiores ao esperando nos estudos.

Informações sobre o Índice de Qualidade de Dickson estão apresentadas na figura 6. Observa-se que os tubetes estudados não influenciaram no IQD, pois não há diferença estatística pelo teste $\mathrm{T}$ de Student para as mudas para os diferentes tratamentos.

Figura 6. Índice de Qualidade de Dickson para as mudas de aroeira durante o experimento.

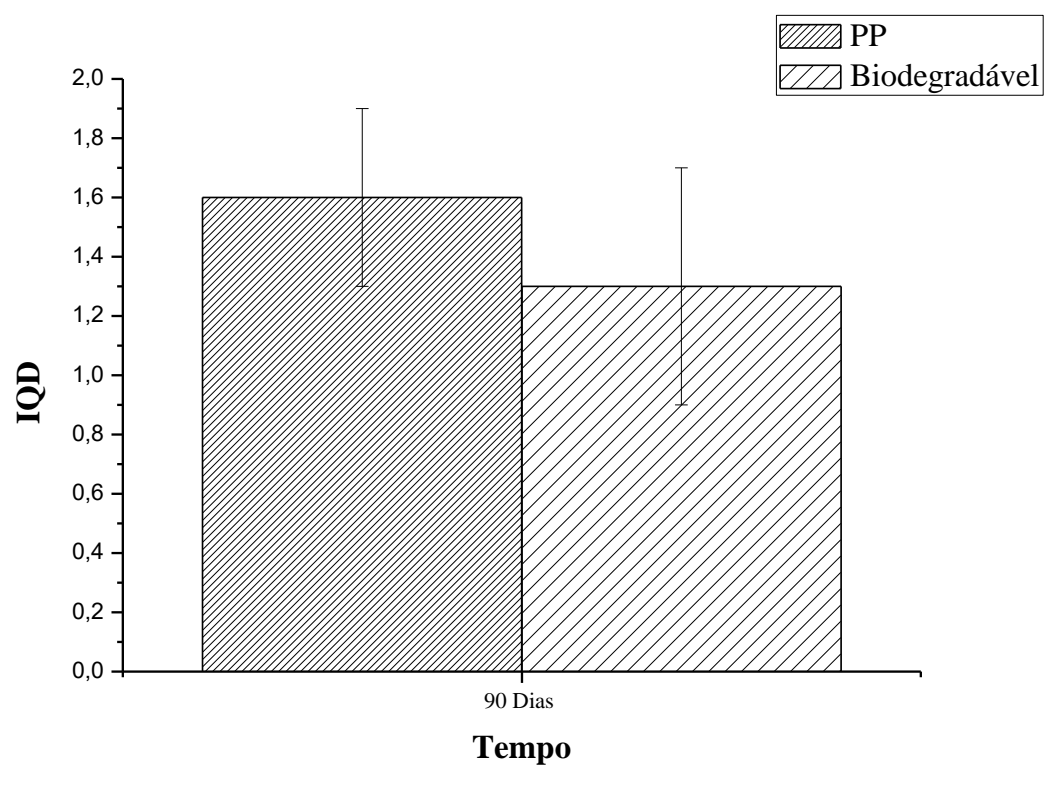

Cabe salientar que o IQD não apresentou diferença estatística entre os tratamentos, porém apresenta valores dentro do recomendado pela literatura para espécies nativas. Hunt (1990) e Birchler et al. (1998) recomendam que o índice de qualidade de Dickson para espécies florestais em viveiro deve ser menor que 10 e maior que 0,2 , respectivamente, para que a muda apresente alta qualidade, ou seja alta taxa de crescimento e sobrevivência após o plantio.

Resultados similares de IQD foram encontrados em estudos sobre o crescimento de mudas de espécies nativas realizados por Aguiar et al. (2011) e Alves e Freire (2017), por exemplo.

O Índice de Qualidade de Dickson (IQD) é considerado um dos índices mais completos para avaliação da qualidade de mudas florestais, pois inclui em seu cálculo as relações entre os parâmetros morfológicos altura, diâmetro, peso da matéria seca aérea e peso da matéria seca radicular, além da biomassa total (ABREU et al., 2019). No entendimento de José et al. (2005), quanto maior seu valor, maior é o grau de qualidade da muda, dentro daquele lote.

Para Vieira et al. (2019), o IQD representa um bom informativo no que diz respeito à qualidade das mudas, visto que em seu cálculo se leva em conta a robustez e, também, o equilíbrio na distribuição da biomassa nas mudas, ponderando os resultados das importantes variáveis empregadas para a avaliação da qualidade. 


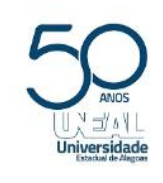

Conclusões

\section{Revista Ambientale}

Revista da Universidade Estadual de Alagoas/UNEAL

Diante dos resultados apresentados, conclui-se que as mudas de espécies florestais de aroeira não apresentaram diferença estatística entre os tipos de tubetes para todos os parâmetros de altura, diâmetro do colo, massa seca da parte aérea, massa seca da raiz e índice de qualidade de Dickson.

Por outro lado, houve diferença estatística entre os tubetes apenas para o índice de rusticidade, sendo que as mudas de aroeira tiveram melhor índice para o tubete biodegradável.

Além disso, os tubetes biodegradáveis mantiveram sua integridade física durante toda a permanência em viveiro florestal, mesmo submetido ao manuseio e às condições ambientais de temperatura, umidade e radiação solar.

Portanto, tais tubetes biodegradáveis podem ser utilizados para a produção de mudas em viveiro florestal, pois não influenciaram negativamente nos parâmetros de crescimento e desenvolvimento de mudas de espécies florestais nativas, ou seja, os tubetes biodegradáveis não se degradaram durante sua permanência em viveiro, permitindo o crescimento até que as mudas atingissem os parâmetros necessários para ir a campo.

\section{Conflito de interesses}

Os autores deste manuscrito não declararam conflitos de interesse.

\section{Referências}

ABREU, A. H. M.; LELES, P. S. S.; MELO, L. A.; FERREIRA, D. H. A. A.; MONTEIRO, F. A. S. Produção de mudas e crescimento inicial em campo de Enterolobium contortisiliquum produzidas em diferentes recipientes. Revista Floresta, v. 45, n. 1, p. 141150, 2015.

AGUIAR, F. F. A.; KANASHIRO, S.; TAVARES, A. R.; NASCIMENTO, T. D. R.; ROCCO, F. M. Crescimento de mudas de pau-brasil (Caesalpinia echinata Lam.), submetidas a cinco níveis de sombreamento. Ceres, v. 58, n. 6, p. 729-734, 2011.

ALVES, F. J. B.; FREIRE, A. L. O. Crescimento inicial e qualidade de mudas de ipê-roxo (Handroanthus impetiginosus (Mart. Ex DC) Mattos) produzidas em diferentes substratos. Revista Agropecuária Científica no Semi-Árido, v. 13, n. 3, p. 195-202, 2017.

AMORIM, M. M. R.; SANTOS, L. C. Tratamento da vaginose bacteriana com gel vaginal de Aroeira (Schinus terebinthifolius Raddi): ensaio clínico randomizado. Revista Brasileira de Ginecologia e Obstetrícia, v. 25, n. 2, p. 95-102, 2003. 
ANDERSON, S.; ZHANG, J.; WOLCOTT, M. P. Effect of interfacial modifiers on mechanical and physical properties of the PHB composite with high wood flour content. J. Polym Environ, v. 21, n. 1, p. 631-639, 2013.

ANTONIAZZI, A. P.; BINOTTO, B.; NEUMANN, G. M.; SAUSEN, T. L.; BUDKE, J. C. Eficiência de recipientes no desenvolvimento de mudas de Cedrela fissilis Vell. (Meliaceae).

Revista Brasileira de Biociências, v. 11, n. 3, p. 313-317, 2013.

BIRCHLER, T.; ROSE, R.W.; ROYO, R.; PARDOS, M. La planta ideal: revision del concepto, parametros definitorios e implementaction practica. Investigacion Agraria, Sistemas y Recursos Forestales, v. 7, n. 1, p. 109-121, 1998.

BRANT, A. J. C.; Naime, N.; Lugão, A. B. Tubetes biodegradáveis fabricados a partir de compósitos de Biopolímero e bagaço de cana-de-açúcar. In: $12^{\circ}$ Congresso Brasileiro de Polímeros, 2011.

BRASIL. Ministério da Agricultura, 1972. Levantamento exploratório, reconhecimento de solos do Estado da Paraíba. Boletim Técnico, 15. Rio de Janeiro: MA/CONTA/USAID/ SUDENE.

CARGNELUTTI FILHO, A.; ARAÚJO, M. M.; GASPARIN, E.; FOLTZ, D. R. B. Dimensionamento Amostral para Avaliação de Altura e Diâmetro de Plantas de Timbaúva. Floresta e Ambiente, v. 25, n. 1, p. 1-9, 2018.

CARMELLO-GUERREIRO, S.M.; PAOLI, A. A. S. Ontogeny and Structure of the Pericarp of Schinus terebinthifolius Raddi (Anacardiaceae). Brazilian Archives of Biology and Technology, v.45, n.1, p.73-79, 2002.

CARneIRO, J. G. A. Produção e Controle de Qualidade de Mudas Florestais. Curitiba: UFPR/FUPEF, 1995. 451p.

CORADIN, L.; CAMILLO, J.; PAREYN, F. G. C. Espécies nativas da flora brasileira de valor econômico atual ou potencial: plantas para o futuro: região Nordeste. Brasília, DF: MMA, 2008. 1311p.

COSTA, E. G.; BARRETO, C. F.; FARIAS, R. M.; MARTINS, C. R. Propagação de amoreira-preta em diferentes substratos e estimuladores de enraizamento. Brazilian Journal of Development, v. 6, n. 6, p. 36654-36662, 2020.

DICKSON, A.; LEAF, A. L.; HOSNER, J. F. Quality appraisal of white spruce and white pine seedling stock in nurseries. Forest Chronicle, v. 36, n. 1, p. 10-13, 1960.

FERRAZ, M. V.; CEREDA, M. P.; IATAURO, R. A. Produção de mudas de petúnia comum em tubetes biodegradáveis em substituição aos sacos plásticos. Brazilian Journal of Biosystems Engineering, v. 9, n. 1, p. 74-83, 2015. 


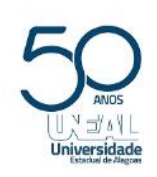

\section{Revista Ambientale}

Revista da Universidade Estadual de Alagoas/UNEAL e-ISSN 2318-454X, Ano 12, Vol. 12 (3), julho/outubro (2020).

GOMES, A. D. V.; FREIRE, A. L. O. Crescimento e qualidade de mudas de cedro (Cedrela fissilis L.) Em função do substrato e sombreamento. Scientia Plena, v. 15, n. 11, p. 1-9, 2019.

GOMES, S. H. M.; GONÇALVES, F. B.; FERREIRA, R. A.; PEREIRA, F. R. M.; RIBEIRO, M. M. J. Avaliação dos parâmetros morfológicos da qualidade de mudas de Paubrasilia echinata (pau-brasil) em viveiro florestal. Scientia Plena, v. 15, n. 1, p. 11-17, 2019.

GUERRA, M. S.; BARBOSA, M. S.; COSTA, E.; VIEIRA, G. H. C. Recipiente biodegradável e substratos para mudas de maracujazeiro. Revista de Agricultura Neotropical, v. 4, n. 3, p. 50-54, 2017.

JOSÉ, A. C.; DAVIDE, A. C.; OLIVEIRA, S. L. Efeito do volume do tubete, tipo e dosagem de adubo na produção de mudas de aroeira (Schinus terebinthifolia Raddi). Agrarian, v. 2, n. 3, p. 73-86, 2009.

LORENZI, H. Árvores brasileiras: manual de identificação e cultivo de plantas arbóreas do Brasil. São Paulo: Nova Odessa, v. 2, 368p. 1998.

LORENZI, H.; MATOS, F. J. A. Plantas Medicinais no Brasil: nativas e exóticas. 2.ed. Nova Odessa: Instituto Plantarum, 2008. 577p.

MARINHO, P. H. A.; SOUZA, R. M.; GIONGO, M.; VIOLA, M. R.; SOUZA, P. B. Influence of different substrates on seedling production in the flamboyant Delonix regia (Bojer ex Hook) Raf. Revista Agroambiente, v. 11, n. 1, p. 40-46, 2017.

MEIRELES, F.; CÉSPEDES, G.; EGEA-ELSAN, J.; SPICHIGER, R. Estudios fitosociológicos en el Gran Chaco: estructura, composición florística y variabilidad del bosque de Schinopsis balansae en el chaco húmedo boreal, Paraguay. Bonpladia, v. 29, n. 1, p. 39-56, 2020.

MOREIRA, E. J. C.; MELO, L. A.; TEIXEIRA, L. A. F. Utilização de tubetes biodegradáveis na produção de mudas de espécies Florestais nativas. In: Anais da Reunião Regional da SBPC em Lavras / MG, 2010.

NOVAES, A. B.; SILVA, H. F.; SOUSA, G. T. O.; AZEVEDO, G. B. Qualidade de mudas de nim indiano produzidas em diferentes recipientes e seu desempenho no campo. Floresta, v. 44, n. 1, p. 101-110, 2014.

OLIVEIRA, M. A.; FIORINE, R. A. Análise de crescimento em mudas de mandioca (Manihot esculenta Crantz) provenientes de estacas em diferentes recipientes para cultivo. Revista raízes e amidos tropicais, v. 2, n. 1, p. 12-26, 2006.

OLIVEIRA, M. C.; OGATA, R. S.; ANDRADE, G. A.; SANTOS, D. S.; GUIMARÃES, T. G.; SILVA JÚNIOR, M. C.; PEREIRA, D. J. S.; RIBEIRO, J. F. Manual de viveiro e produção de mudas: espécies arbóreas nativas do Cerrado. Rede de Sementes do Cerrado, Brasília, 2016. 


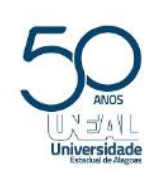

\section{Revista Ambientale}

Revista da Universidade Estadual de Alagoas/UNEAL e-ISSN 2318-454X, Ano 12, Vol. 12 (3), julho/outubro (2020).

PAIVA, J. N.; BRAGA, R. S. S.; SANTANA, J. A. S.; CANTO, J. L. Crescimento e sobrevivência de Genipa americana L. No município de Macaíba (Rio Grande do Norte Brasil). Revista Brasileira de Meio Ambiente, v. 7, n. 3, p. 88-93, 2019.

PAIVA SOBRINHO, S.; LUZ, P. B.; SILVEIRA, T. L. S.; RAMOS, D. T.; NEVES, L. G.; BARELLI, M. A. A. Substratos na produção de mudas de três espécies arbóreas do cerrado. Revista Brasileira de Ciências Agrárias, v.5, n.2, p.238-243, 2010.

PAREYN, F.G.C.; ARAUJO, E.L.; DRUMOND, M.A.; MIRANDA, M.J.A.C.; SOUZA, C.A.; SILVA, A.P.S.; BRAZOLIN, S.; MARQUÊS, K.K.M. Espécies nativas da flora brasileira de valor econômico atual ou potencial: plantas para o futuro: região Nordeste. Brasília, 2018. Cap. 5, p. 766-772.

OliveIRA, M. F.; SIlvA, E. C.; CATUNDA, P. H. A.; SilvA, E. S.; LEITE, N. S. Emergência de plântulas e desenvolvimento inicial de mudas de aroeira sob diferentes substratos. Brazilian Journal Development, v. 6, n. 8, p. 56093-56105, 2020.

SANTANA, J. A. S.; COSTA, T. L. N.; SILVA, B. R. F.; BARBOSA JÚNIOR, V. C.; COSTA, M. P.; CANTO, J. L. Use of biodegradable bamboo containers in development of Enterolobium contortisiliquum (Vell.) Morong seedlings. Brazilian Journal of Development, v. 5, n. 9, p. 15912-15921, 2019.

SCHEER, M. B.; CARNEIRO, C.; BRESSAN, O. A.; SANTOS, K. G. Crescimento inicial de quatro espécies florestais nativas em área degradada com diferentes níveis de calagem e de adubação. Revista Floresta, v. 47, n. 3, p. 279-287, 2017.

ROCHA, J. H. T.; BACKERS, C.; DIOGO, F. A.; PASCOTTO, C. B.; BORELli, K. Composto de lodo de esgoto como substrato para mudas de eucalipto. Pesquisa Florestal Brasileira, v. 33, n. 73, p. 27-36, 2013.

RODRIGUES, A. B. M.; GIULIATTI, N. M.; PEREIRA JÚNIOR, A. Aplicação de metodologias de recuperação de áreas degradadas nos biomas brasileiros. Braz. Ap. Sci. Rev. v. 4, n. 1, p. 333-369, 2020.

SILVA, M. M.; SILVA, V. J.; RODRIGUES, M. G. F. Caracterização da cinza da casca de arroz visando sua aplicação na adsorção de poluentes orgânicos. In: Anais do $2^{\circ}$ Congresso Químico do Brasil, 2012. 